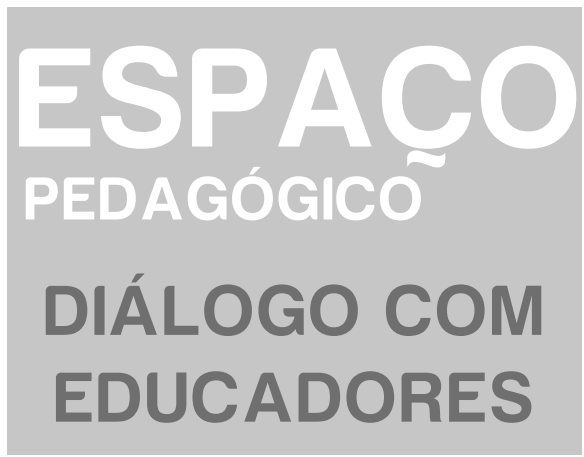





\section{Diálogo com educadores ${ }^{1}$}

António Teodoro

Na seção Diálogo com educadores deste volume da Revista Espaço Pedagógico, contamos com a instigante entrevista concedida pelo professor e pesquisador António Teodoro, doutor em Ciências da Educação pela Universidade Nova de Lisboa. Atualmente, é professor de Sociologia da Educação e Educação Comparada e diretor do Centro de Estudos Interdisciplinares em Educação e Desenvolvimento (CeiED), da Universidade Lusófona de Portugal. Foi Vice-Presidente do Comité de Investigação de Sociologia da Educação (RC04) da Associação Internacional de Sociologia (2006-2014) e co-fundador do Instituto Paulo Freire, de Portugal. Nosso entrevistado é autor de uma vasta obra científica e de intervenção no campo da educação, publicada em diversas línguas.

EP: Iniciamos este diálogo conhecendo um pouco de sua vida: onde nasceu? Como foi sua infância e adolescência? Qual era o contexto sociocultural e político da época?

António Teodoro: Nasci em 1950, numa ilha dos Açores, Faial, numa cidade muito bonita, chamada Horta. Meu pai era marinheiro, da Marinha de Guerra, e minha mãe era "nativa" da ilha, filha de um agricultor. Provavelmente, meu avô materno seria descendente de holandeses, que, no século XVII, fugidos das lutas religiosas que se desenrolavam no norte da Europa, procuravam chegar ao Novo Mundo. Tendo aportado à ilha do Faial, foram-lhes oferecidas terras e fundaram a freguesia dos Flamengos (ou habitantes da Flandres).

Na minha infância, acompanhei as promoções do meu pai na Marinha, pois sempre que era promovido, precisava mudar de unidade. Depois de vir para Lisboa, estudei num liceu tradicional de Lisboa, o Gil Vicente. Era um apaixonado pela atividade desportiva. A educação, para mim e para meus dois irmãos, representou uma forma de ascensão social. Os meus pais fizeram todos os sacrifícios para possibilitar os estudos dos filhos. Meu pai tinha feito o ensino primário, o correspondente ao vosso ensino fundamental, o $4^{\circ}$ ano, somente quando tinha 14 anos. Grande parte dos seus irmãos era analfabeta. Ele não. Só depois de chegar

\footnotetext{
Recebido em: 15/09/2016 - Aprovado em 29/11/2016
}

http://dx.doi.org/10.5335/rep.v24i1.7001 
à cidade de Lisboa, entre os 10 e 14 anos, é que se conseguiu escolarizar. Para ele, a educação era a forma de deixar um futuro melhor aos filhos. Hoje, os seus três filhos são doutorados e professores universitários. Infelizmente, morreram relativamente novos, pelo que não viram os seus três filhos atingir os mais reservados (e elevados) escalões da academia portuguesa.

Quando terminei o liceu, tinha duas possibilidades: ou ia para a Escola Naval e, desse modo, seguia a carreira da Marinha de Guerra, como era a aspiração do meu pai, ter um filho oficial, ou, como era apaixonado pelo desporto, podia ir para o Instituto Nacional de Educação Física. Foi esta segunda via que segui. Muito jovem, contudo, me envolvi na atividade política, quase ao mesmo tempo que me interessei pela história e a sociologia. Vivi um momento ímpar para qualquer português, que foi a Revolução de 25 de abril de 1974, a Revolução dos Cravos. E numa situação muito particular. Era oficial da Marinha, onde cumpria o serviço militar obrigatório. Como estudante, tinha estado ligado aos movimentos de oposição ao regime, tendo entrado para o Partido Comunista Português logo nos primeiros dias após a revolução. Na Marinha, trabalhei primeiro na Comissão de Extinção da PIDE-DGS (a polícia política da ditadura) e, depois, num órgão do Conselho da Revolução. Aí, trabalhei muito próximo do núcleo do poder político-militar revolucionário, acompanhando alguns amigos da Comissão Coordenadora do Movimento das Forças Armadas.

Com 24 anos de idade, fui requisitado à Marinha para o Ministério da Educação, ocupando o cargo de Inspetor-Chefe do Ensino Primário durante uns meses. Participei numa equipa maravilhosa coordenada pelo Professor Rogério Fernandes, que fez grandes mudanças na formação dos professores, nos conteúdos da educação, na democratização da educação nos primeiros anos de escolaridade. Saí da Marinha, definitivamente, em 1976, regressando à atividade docente no ensino secundário. Retomei a militância sindical. Antes ainda da revolução, tinha estado na origem do movimento que veio dar origem aos sindicatos dos professores. Fui um dos fundadores do movimento sindical dos professores. Em 1979, fui eleito Presidente do Sindicado da região de Lisboa. Depois, fui o primeiro Secretário-Geral da Federação Nacional dos Professores (Fenprof), durante vários mandatos e até 1994. Durante muitos anos, fui o rosto da principal organização sindical dos professores portugueses, ou seja, a minha história de vida até meados dos anos de 1990 confunde-se com a luta dos professores e, particularmente, com a afirmação dos professores como grandes players políticos na vida portuguesa. Em Portugal, os professores têm uma grande influência e participação política. E, no período pós-revolucionário, a sua influência ainda era maior. $\mathrm{O}$ movimento sindical dos professores em Portugal é extremamente forte e respeitado. A minha carreira uni- 
versitária é posterior à minha intensa participação político-sindical. Fiz o mestrado quando ainda desempenhava funções sindicais, mas o doutoramento já foi feito logo após a minha demissão de Secretário-Geral da Fenprof.

EP: Fale-nos de sua grande atuação no movimento sindical na década de 1970.

António Teodoro: Como disse antes, fui um dos fundadores do movimento que deu origem aos sindicatos dos professores. Esse movimento, reunido em torno de grupos de estudo, desenvolveu uma ação alegal, pois os professores, como todos os funcionários públicos, estavam proibidos de se associar e de defender os seus interesses sócio-profissionais. Isso foi em 1971, três ou quatro anos antes da revolução. Depois, em 1974, mesmo sendo militar, participei ativamente na constituição dos sindicatos dos professores. Só interrompi a militância sindical quando fui para o Ministério da Educação. Em 1979, fui eleito Presidente do Sindicato dos Professores da Grande Lisboa e, em 1983, estive na origem da Federação Nacional dos Professores, sendo seu Secretário-Geral até 1994. Pode-se dizer que, durante quase duas décadas, fui o principal rosto dos professores portugueses representados pelo seu movimento sindical. A Fenprof era, e mantém-se, a mais importante e representativa organização de professores, da educação pré-escolar à universidade.

EP: E como foi sua atuação no Conselho Nacional de Educação no final dos anos 1980 ?

António Teodoro: Fui membro do Conselho Nacional de Educação em representação dos professores e do movimento sindical. Participei na instalação do conselho e na sua consolidação como órgão consultivo no campo das políticas de educação. O Conselho Nacional de Educação em Portugal tem uma composição e funções muito diferentes das do CNE do Brasil. No Brasil, o CNE tem funções de avaliação e de acreditação das instituições, nomeadamente no ensino superior, para além da emissão de pareceres sobre políticas. Em Portugal, é só um órgão consultivo. A forma como é constituído também é muito diferente. Os membros não são nomeados pelo Presidente. São as organizações sociais que indicam, para além dos membros indicados pelo Governo ou pelo Parlamento. Há representantes indicados diretamente pelos professores a dois níveis: do movimento sindical, mas também de associações pedagógicas e científicas. Os pais também têm representantes indicados. A minha participação no conselho foi como representante dos professores e do movimento sindical. 
EP: O senhor também teve envolvimento com o Centro de Estudos Sociais na Universidade de Coimbra e se envolveu no grande projeto intitulado "A sociedade portuguesa perante os desafios da globalização". Como foi esse envolvimento e de que forma esse centro contribuiu com as suas percepções sobre a educação?

António Teodoro: O Centro de Estudos Sociais, como se sabe, foi fundado e ainda hoje é dirigido e marcado pela personalidade de Boaventura de Sousa Santos. Logo após a minha saída de Secretário-geral da Fenprof, e quando tinha uma bolsa do Ministério da Educação para fazer o meu doutoramento na Universidade Nova de Lisboa, fui convidado para participar no projeto que refere, e que era dirigido por Boaventura de Sousa Santos. Acontece que o Centro de Estudos Sociais não tinha (e ainda não tem) uma equipa forte no campo da educação, pelo que o Boaventura pediu ao Steve Stoer, professor da Universidade do Porto, que constituísse uma equipa para integrar esse grande projeto, onde participavam cerca de 100 investigadores, de todas as áreas, da cultura, à economia ou à política, e originários de várias universidades e não apenas da Universidade de Coimbra. A equipa da educação era constituída na sua maioria por pessoas da Universidade do Porto, como o José Alberto Correa ou a Luíza Cortesão. Possivelmente, por estar a trabalhar com o Steve Stoer, participei dessa equipa. Nessa altura, estava a fazer o doutoramento, trabalhando algumas das questões que estavam no centro do projeto, como a transnacionalização da educação. O projeto que refere teve um particular significado no plano teórico, pois é onde se constrói o conceito de globalização, melhor de globalizações, que Boaventura de Sousa Santos veio a tornar muito popular e conhecido no Brasil e em toda a América Latina. É nesse projeto que se abandona a ideia de uma globalização no singular, adoptando-se o conceito de globalizações no plural, hegemónicas e contra-hegemónicas nos seus modos de afirmação e desenvolvimento. Boaventura, enquanto coordenador do projeto (e produtor do conceito), veio a popularizar na comunidade acadêmica esse tipo de abordagem, hoje geralmente aceite na generalidade dos quadros teóricos. A equipa da educação trabalhou a questão da transnacionalização da educação. Na altura, adaptei uma proposta de Boaventura de que havia globalizações de alta e de baixa intensidade. Em trabalho publicado no âmbito do projeto, descrevi as políticas de educação como um fenómeno de baixa intensidade. Esse foi um período muito rico na minha vida. Tinha terminado um tempo de grande intensidade de participação política e sindical, e dedicava-me inteiramente ao estudo e à investigação. Foi também um período muito rico no plano político, o que me permitiu uma transição do campo da política (onde o sindicalismo se insere dominantemente) para o da academia. Passei a olhar muitas das questões em que sempre estive envolvido já não como ator, mas como cientista social. 
EP: Conte-nos um pouco sobre as suas experiências docentes. Sabemos que o senhor foi professor inclusive na educação básica. Poderia também nos falar sobre a relação entre ensino e pesquisa?

António Teodoro: Fui professor de Educação Física antes mesmo de terminar o curso, até para poder estudar. Nesses tempos, na transição dos anos sessenta para setenta do século XX, havia muita falta de professores. Trabalhei primeiro num liceu em Almada e, depois, quando não fui reconduzido devido ao meu ativismo (para)sindical, fui convidado pelo Professor Calvet de Magalhães, diretor da Escola Francisco Arruda, para trabalhar em part time nessa escola de Lisboa. Mesmo depois de ir para a Marinha, aos fins de semana, ainda dava umas aulas de Iniciação Desportiva na Escola Francisco de Arruda. Na Marinha, era Técnico Especialista em Educação Física, onde, depois da preparação militar na Escola Naval, fui responsável pelos Serviços de Educação Física de uma grande unidade militar (o Grupo no 2 de Escolas da Armada) na margem sul do Tejo. Aí, no meio de uma intensa participação política, pude usufruir uma minha outra paixão: o futebol. Em 1975, fui treinador-jogador da equipa dessa unidade naval, que ganhou o Campeonato de Futebol da Armada, conquista que não acontecia há vários anos. O futebol, sobretudo em nível do treino, era outra das minhas paixões. Possivelmente, se não fosse a política, hoje poderia ser treinador de futebol. Posso dizer que tinha algum jeito para aquilo e tinha algum conhecimento, sobretudo no campo do treino e da liderança de pessoas. Quando saí da Marinha, regressei à condição de professor do ensino secundário, onde, durante dois ou três anos, fui professor de Educação Física. Como disse antes, em 1979 fui eleito Presidente da Direção do Sindicato dos Professores da Grande Lisboa. Ainda tentei conciliar as aulas com a vida sindical, mas tal não era compatível. Tinha uma atividade muito intensa, com muitas reuniões por todo o país e no estrangeiro, o que não era compatível com as aulas em dias e horas fixas da semana. A vida sindical, ao mais elevado nível de responsabilidades, significa um conjunto imenso de reuniões, de conferências de imprensa, de deslocações. E para alguém como eu, que tem uma obsessão pela pontualidade e por nunca faltar a uma aula, tal implicava uma opção, que foi a de ficar a tempo inteiro no sindicato. Só voltei a dar aulas, efetivamente, depois de terminar o meu mandato sindical, agora já na universidade e não no ensino secundário. O sindicato foi uma poderosa escola de formação. Tanto a Fenprof como o Sindicato da Grande Lisboa representavam educadores e professores da educação da infância à universidade, obrigando-me a um conhecimento aprofundado de todas essas áreas, não apenas no campo das reivindicações profissionais, mas igualmente no das políticas de educação. Posso dizer, sem autoelogio, que fui um dos principais protagonistas no debate educativo em Portugal durante as décadas de oitenta e noventa. 
EP: No campo da pesquisa, quais são as problemáticas com que o senhor tem se ocupado mais recentemente?

António Teodoro: Hoje, como muitos de nós que vieram da Sociologia da Educação, estamos a trabalhar áreas que podem ser designadas por Educação Comparada, ou Educação Comparada e Internacional, como se designa nos EUA. Em geral, quem trabalha com Educação Comparada ou vem da História ou vem da Sociologia. Esta mudança de rumo, ou este novo rumo, dos cientistas sociais da educação para a Educação Comparada decorre, fundamentalmente, das grandes mudanças que, desde o final do século XX, têm vindo a afetar os Estados nacionais e a própria forma desses Estados, isto é, hoje não se pode analisar as políticas públicas de educação exclusivamente no âmbito nacional, ou seja, temos de tomar sempre outras escalas de análise, nomeadamente transnacionais. É o que vulgarmente se dizia por globalização, ou, como prefiro, no plural, por globalizações. Presentemente, as minhas pesquisas inserem-se muito neste campo. Um dos temas que me preocupa há cerca de dez anos são os efeitos (e os impactos) das avaliações estandardizadas, não apenas nas políticas nacionais, mas igualmente na criação de uma agenda mundial. E a criação de agenda mundial é feita a partir da formulação dos próprios problemas, como bem sabem aqueles que orientam teses de mestrado e doutoramento. A questão central está em quem define o problema. Quem define o problema controla os significados. As organizações internacionais que conduzem esses testes estandardizados estão hoje a controlar os significados, pois são elas que definem os problemas, utilizando o mecanismo poderosíssimo da avaliação. Quem controla é quem escolhe os indicadores. Essa tem sido uma das minhas grandes preocupações, a escolha dos indicadores, daquilo que é avaliado e comparado. É isso que está no núcleo da construção dos significados da nova agenda mundial de educação.

Mais recentemente, vi aprovado um Grupo de Trabalho sobre Universidades e Políticas de Educação Superior no âmbito do CLACSO, que coordeno com um colega do Chile. Há também outro projeto em que participo, financiado pela Comissão Europeia, mas que é coordenado pela Universidade de Barcelona, sobre a formação dos professores. Mas a minha preocupação principal continua a ser como se constroem as agendas educativas, como se formulam os problemas da educação em diferentes contextos do sistema mundial.

EP: Sabemos que o senhor tem um conhecimento muito grande acerca do Brasil, então, diga-nos como percebe essa relação entre Brasil e Portugal nos aspectos acadêmico-científicos e de que forma poderíamos avançar nessa relação entre esses dois países? 
António Teodoro: Desculpe, um acrescento antes de responder à sua pergunta. Esqueci-me de referir que, presentemente, tenho uma grande preocupação, que tenho vindo a abordar em alguns textos de intervenção e em várias conferências, nomeadamente no Brasil. É sobre o conceito de justiça e, muito particularmente, o que é justiça no campo da educação. Se quiser, esta minha preocupação insere-se numa estreita relação entre a produção de ideias e a ação política. Dito de outro modo: utilizando a velha (mas atual) distinção de Bobbio entre direita e esquerda, o que são políticas de esquerda, o que as definem e o que as distinguem relativamente a políticas de direita. A(s) esquerda $(\mathrm{s})$ aparece $(\mathrm{m})$ normalmente $\operatorname{associada}(\mathrm{s})$ ao combate às desigualdades e à luta pela emancipação humana. Tenho defendido que, em educação, o combate pela justiça social é, sobretudo, uma luta pela justiça cognitiva, como parte da justiça social, como inerente a um projeto de emancipação humana. A intervenção do cientista (social) não é neutra. A produção de ideias, de teorias, de quadros explicativos, é também poderoso instrumento de transformação social. Por isso, defendo que é responsabilidade inalienável dos cientistas sociais construírem ideias e teorias que ajudem na transformação social. Num tempo em que se apregoa o fim das ideologias, num país como o Brasil, onde é (quase) impossível distinguir esquerda e direita, é fundamental que se clarifique essa distinção em termos de projetos políticos. A minha tese é que a distinção encontra-se na questão da justiça social. E, nos campos da educação, da cultura e da formação, isso significa justiça cognitiva. Que lugar ocupa essa justiça cognitiva nos programas políticos? Devo reconhecer que, nos últimos tempos, a esquerda, campo de onde venho e me filio, perdeu muitas referências teóricas e tem sido bem preguiçoso em construir novas ideias, que sejam transformadoras e mobilizadoras da ação humana. Sei que os tempos que vivemos são muito difíceis. Mas essas dificuldades não justificam tudo!

Indo agora à sua questão, a das relações entre Portugal e Brasil, podemos analisar essas relações em dois domínios: o político e o académico-científico. Comecemos pelo domínio político. Tive o privilégio de trabalhar diretamente com o então Primeiro Ministro de Portugal, Engo António Guterres (que é atualmente o Secretário-Geral das Nações Unidas), no final dos anos de 1990. Nessa altura, em Portugal, passámos de um discurso retórico sobre a saudade e a língua comum nas relações com o Brasil, para se entender o Brasil como uma prioridade econômica, uma prioridade política e, também, uma prioridade cultural. No plano económico, tal significou o investimento de grandes empresas portuguesas no Brasil, desde a compra da operadora Vivo, até a compra de redes de comércio de retalho, o aumento das ligações aéreas da companhia portuguesa TAP a diferentes cidades brasileiras, impulsionando nomeadamente o turismo no Nordeste. Portugal, um pequeno país 
europeu, chegou a ser o quarto investidor estrangeiro no Brasil. Isso representou uma mudança face aos governos anteriores de Cavaco Silva, um político conservador, que defendia uma aposta prioritária em Espanha e na Europa em geral. Foi no quadro dessa prioridade que o estreitamento das ligações entre universidades se veio a realizar. No plano político, tive, como disse, o privilégio de estar no centro dessa discussão política, de ver os primeiros passos de uma passagem de um discurso retórico a uma relação com fortes laços econômicos, culturais e políticos. Nesse período, houve dimensões e acontecimentos que foram particularmente importantes para facilitar essa aproximação. Para os portugueses, a riqueza da música brasileira, em especial dos seus ícones da MPB, e a passagem na televisão, com enormes audiências, da primeira novela, a Gabriela Cravo e Canela, de Jorge Amado, representada por Sônia Braga no esplendor da sua beleza e sensualidade. Para os brasileiros, a atribuição do Prémio Nobel da Literatura a José Saramago, a entrada de Portugal para a Comunidade Europeia, a realização da Exposição Universal em Lisboa, a modernização da sociedade portuguesa fez com que muitos brasileiros, nomeadamente as suas elites, deixassem de olhar para Portugal como a terra do Manoel e do Joaquim das anedotas, esses camponeses pobres, pouco escolarizados e nada cultos, que tudo arriscaram e para aqui vieram ser padeiros, trabalhar na construção civil, abrir um pequeno comércio. Essas elites, ou parte delas, passaram a olhar Portugal de uma outra forma. É neste contexto que se vai dar a aproximação entre as universidades. Isso foi/é útil para Portugal, mas foi/é também muito útil para o Brasil. Recentemente, um estudo da principal empresa bibliométrica norte-americana, a Thomson Reuters, sublinhava que o Brasil e as universidades brasileiras tinham ganho muito com o contato com as universidades portuguesas. E por quê? A tese defendida nesse estudo era de que isso não resultava do fato das universidades portuguesas serem muito melhores que as brasileiras, ou de figurarem nos rankings em lugares cimeiros. $\mathrm{O}$ argumento era o de que Portugal, as universidades portuguesas, pela sua dimensão média, pela ausência de pretensões neocoloniais em relação ao Brasil, pela proximidade de culturas, permitia às universidades brasileiras (e aos seus professores e cientistas) uma internacionalização bem sucedida. Melhor sucedida do que o contato com outras universidades dos primeiros lugares dos rankings. Há uma compreensão, uma proximidade, que facilita a cooperação e que ajudou essas universidades (e universitários) brasileiras a crescerem cientificamente e a internacionalizarem-se. E a afirmar o Português como língua não apenas de cultura, mas também de ciência. Para as universidades portuguesas há também um outro e importante aspecto: o Brasil é um enorme campo de recrutamento de alunos de pós-graduação, a nível de mestrado e doutorado. O doutoramento que dirijo, em Educação, tem 67\% de 
estudantes estrangeiros, dos quais $57 \%$ são brasileiros. Isso decorre, em grande medida, das extremas dificuldades que, no Brasil, se tem em aceder a programas de pós-graduação stricto sensu. As universidades portuguesas, entre as quais a minha, tem no Brasil uma forte e importante fonte de recrutamento de estudantes.

EP: Como o senhor percebe os efeitos da globalização e da transnacionalização na organização do ensino superior dos países lusófonos, latino-americanos?

António Teodoro: Num livro que está publicado aqui no Brasil, A educação em tempos de globalização neoliberal, saído na Editora Liber Livros, de Brasília, defendo a seguinte tese: o neoliberalismo não é só uma teoria econômica, é uma racionalidade, que penetra em todos os domínios e em todas as esferas, nomeadamente na esfera social e na esfera educativa. Em parênteses, esclareço que esse livro resultou das minhas provas de agregação, o correspondente no Brasil à livre docência, que teve, precisamente, como debatedor, nessa parte, Boaventura de Sousa Santos. E o que é que isso tem a ver com a sua pergunta? A essência do neoliberalismo é o assumir que os seres humanos só se tornam melhores quando entram em competição. É a transposição para todos os domínios da vida social da ideia de que é a competição que torna os seres humanos melhores. A economia só progride, só aumenta a eficácia das trocas econômicas, pelo mercado e pela competição. Todos os outros valores, como a cooperação, a solidariedade humana, a justiça, desaparecem ou são remetidos para plano secundaríssimo. Por exemplo, no caso da atividade universitária, gerou-se o senso comum de que só somos melhores pesquisadores, ou professores, quando competimos entre nós, nos concursos, na produção científica, na disputa por financiamentos. Para isso se criam todas as plataformas informáticas, como a do o currículo Lattes, para quantificar toda a nossa vida, todos os "produtos". Esta é a génese do produtivismo académico. Os programas de mestrado e doutorado são avaliados de 1 a 7 , as revistas e os livros têm uma classificação Qualis em vários escalões, até os eventos científicos, tudo é pontuado e classificado. No Brasil, esta situação "naturalizou-se", e, como tal, nem se discute. Mesmo entre os colegas que se distinguem pela radicalidade das suas análises, nunca vi isto ser debatido, talvez porque são parte ativa neste processo conduzido por uma tecno-estrutura poderosa como é a Capes, que coopta a comunidade universitária. Mas isto não é assim em todo o lado. Em Portugal, mesmo a nível político, desenvolve-se uma crítica feroz, e fundamentada, ao uso das métricas na avaliação da atividade científica dos professores. Ainda recentemente, uma colega francesa de visita ao Brasil para participar em eventos científicos me transmitia a sua estranheza e perplexidade e esperava que a França se mantivesse 
imune a estas tendências, que se tornam uma espécie de big brother no controlo da atividade dos docentes. Não sei se o conseguirá!

O combate a essa racionalidade deve ser teórico, mas também prático. De forma modesta, nos grupos de pesquisa que tenho coordenado a nível internacional, como a rede RIAIPE, que reuniu pesquisadores de 31 universidades na Europa e na América Latina, temos procurado mostrar que são possíveis outras racionalidades. Procuramos construir o que designamos de comunidade de aprendizagem. A comunidade de aprendizagem traz para primeiro plano a cooperação académica e científica entre professores situados em universidades e países com diferentes níveis de desenvolvimento e com diferentes culturas. A comunidade de aprendizagem valoriza a relevância social das problemáticas pesquisadas. A comunidade de aprendizagem defende a ciência aberta, ou seja, o conhecimento não pode ser privatizado. É possível desenvolver projetos entre a Europa e a América Latina sem ser nos velhos termos neocoloniais de "assistência técnica". A competição estimula, mas a cooperação cria solidariedades, cria redes. E essas redes são também locais de aprendizagem, de transmissão de conhecimento, de transposição para o espaço público do conhecimento produzido. As universidades, e os cientistas (sociais), devem ser um exemplo dessa luta.

Um campo particularmente sensível é o das revistas científicas. Sou um dos fundadores do movimento de revistas científicas independentes, que desenvolve uma atividade de resistência ao oligopólio das grandes editoras mundiais que dominam hoje o mercado de publicação, e que constroem o significado do que é uma publicação internacional. Sou diretor (e fundador) de uma revista que ganhou estatuto internacional (no Brasil é Qualis A1), embora se publique em língua portuguesa. Nós participamos nesse movimento de open science, buscando evitar que estes grandes oligopólios se apossem e tornem a publicação da produção científica no grande negócio do século XXI.

EP: Quais são os desafios e as possibilidades das redes de cooperação institucionais, especialmente no desenvolvimento das atividades de ensino e pesquisa?

António Teodoro: Como disse, desde 2007, coordeno a rede RIAIPE, constituída primeiro com um projeto financiado pelo CYTED, um programa que existe no âmbito da Organização dos Estados Iberoamericanos (OEI), e financiado depois, entre 2011 e 2014, pelo programa ALFA da União Europeia. Agora, estamos com um grupo de trabalho no âmbito do CLACSO, para além de outros projetos de natureza bi e multilateral mais restritos. Do que não abdico é que essas redes devem contribuir para a construção de comunidades de aprendizagem, de comunidades 
de cooperação. Deste modo, é que podem formar melhores pesquisadores, melhores professores, melhor e mais relevante conhecimento.

EP: Lendo seu currículo, lendo alguns de seus textos, sabemos que o senhor trata sobre a questão da internacionalização, e o dossiê no qual será publicada essa entrevista é sobre internacionalização. Quais seriam as mudanças nas concepções e nas atividades de ensino, pesquisa e extensão e mesmo administração, que vêm sendo induzidas na organização das nossas universidades em função da internacionalização?

António Teodoro: Quando, nas minhas aulas de Políticas de Educação Superior, abordo a questão da internacionalização das universidades, costumo recomendar um livro de Fernando Seabra Santos e Naomar de Almeida Filho, publicado em 2012 simultaneamente nas editoras da Universidade de Coimbra e da Universidade de Brasília, intitulado A quarta missão da universidade: internacionalização universitária na sociedade do conhecimento. Como o próprio título indica, os autores defendem que a internacionalização é a quarta missão da universidade. Essa quarta missão da universidade existiu nos primórdios da universidade medieval, que não tinha fronteiras. Os discípulos acompanhavam os seus mestres para onde eles se dirigissem. Na universidade moderna, fortemente influenciada pelo Estado-Nação, houve um retrocesso nessa dimensão de internacionalização. Na América Latina, como em outras partes do mundo, a universidade assume-se como nacional, destinada a formar as novas elites dos países saídos das diferentes colonizações. Reparem nas designações de muitas universidades na América Latina: Universidade Nacional Autónoma do México, das Honduras ou de outros países. A universidade fez parte da construção do Estado-Nação, do Estado construído pós-independência. Nesse contexto, a dimensão da internacionalização foi subalternizada pela questão da formação das elites nacionais responsáveis pela condução e pela formação dos quadros dos novos países saídos da dominação colonial espanhola ou portuguesa. Mas, com os processos que se designam de globalização, ou de globalizações, como prefiro, emergiram agendas transnacionais de forte impacto, nomeadamente no campo da ciência e da produção do conhecimento. O conhecimento científico não tem fronteiras, pelo que a mobilidade de professores e de estudantes cresceu em ritmo acelerado. Os programas de mobilidade na Europa, como o Erasmus, costumam ser referência. Mas o próprio Ciência sem Fronteiras brasileiro é um exemplo dessa ambição e dessa nova realidade.

Falar hoje em universidades nacionais faz pouco sentido, não tem um mínimo de adesão à realidade. Esta internacionalização faz-se, muitas vezes, para além das políticas oficiais dos governos. Faz-se com as bolsas sanduíches, com os pós- 
-doutoramentos, com as vindas de pesquisadores para os congressos internacionais, com uma presença ativa nas comunidades e sociedades científicas. O conhecimento é cosmopolita. E o cosmopolitismo só beneficia a aquisição de conhecimento. Esse cosmopolitismo constitui uma das esperanças positivas num mundo onde tendem a aumentar as manifestações de xenofobia, de racismo e de sexismo. Estão a emergir um conjunto de atores políticos até há bem pouco tempo impensáveis, como Donald Trump, nos EUA, ou, na Europa, a presença nos governos de partidos de extrema direita proto-fascistas, como na Hungria, ou Polônia, etc. Espero que o Brasil não siga esses caminhos depois do impeachment da Presidente Dilma. Veremos se o capitalismo, na sua versão neoliberal, é ou não capaz de coexistir com a democracia, ou se precisa de regimes "musculados" para manter o seu domínio e exploração!

EP: O senhor já mencionou que faz parte das suas pesquisas, qual seria o papel da pesquisa de educação comparada no contexto da internacionalização da educação?

António Teodoro: Quando abordo essa questão, costumo usar um texto de Roger Dale e de Susan Robertson, salvo erro de 2008, onde estes dois conhecidos autores alertam para os quatro ismos que se devem evitar na análise das políticas de educação: o nacional (ismo), o estatal (ismo), o espaço (ismo) e o educação (ismo). O que esses autores (e queridos amigos) nos querem alertar é para a impossibilidade de analisar hoje as políticas públicas apenas no espaço nacional, considerando que o Estado é a única fonte de poder, ou que a educação é uma ilha fechada sobre si própria. Esses autores convidam-nos a entender o papel dos movimentos sociais, do mercado, das consequências das decisões das famílias, a analisar conceitos como o de governance, traduzido no Brasil como "governança". Nos meus textos, prefiro usar "governação".

EP: Estamos vivendo em tempos de emergência de um sistema educacional mundial? E que desafios somos chamados a enfrentar?

António Teodoro: Não sei. Recentemente, participei na criação da Seção de Educação Comparada da Sociedade Portuguesa de Ciências da Educação. A nossa primeira atividade foi uma interessantíssima conferência realizada em janeiro de 2016. Espero vir a publicar em breve um livro com as principais conferências. Esse foi um tema em debate, e com opiniões muito diferentes. Estamos a assistir à emergência de um sistema mundial de educação ou, pelo contrário, existem fortes indicadores de que a presença do Estado Nacional continua a ser marcante? $\mathrm{Na}$ conferência, por exemplo, Andy Green apresentou forte documentação empírica 
para defender que o Estado nacional não está a recuar. De todo o modo, não tenho receio em afirmar que vivemos hoje um tempo onde organizações transnacionais como a OCDE estão a construir conceitos e significados, a partir da capacidade e hegemonia de formularem os problemas, que permitem a existência de uma agenda mundial de educação. Isso é feito e levado à prática fundamentalmente pelos grandes testes internacionais, ondo o PISA é o mais conhecido. A forma como esses testes são replicados nos países e são transformados em políticas locais, estaduais e municipais mostra o seu impacto nos espaços nacionais. Esses conceitos e significados fazem depois o seu curso nas teorias curriculares, na formação dos professores, e em muitos outros campos. Mas as realidades locais podem ser muito distintas desses discursos cosmopolitas. É necessário sempre um exercício de "tradução" para esses contextos. E, no Brasil, isso é mais importante que em outros contextos nacionais. O Brasil não é um país, o Brasil é um continente que, no seu interior, tem muitos "brasis", e não apenas na geografia. Pode-se estar em São Paulo e ter todos os "brasis" dentro de São Paulo: ter o nordeste mais profundo e pobre lado a lado com realidades sociais de enorme riqueza, com uma classe média e alta com hábitos de consumo e de práticas sociais onde coexiste modernidade capitalista e tradições de uma sociedade que se manteve escravocrata até muito tarde. O Brasil tem esses grandes paradoxos, o que obriga aqueles que analisam as políticas públicas a grandes cuidados, de forma a levar em conta essa diversidade, nunca o podendo fazer a partir de modelos pré-construídos. Mesmo os quadros teóricos têm de ser feitos com mediações.

EP: Professor António, muito obrigado por sua disponibilidade em nos conceder não só uma entrevista, mas uma profunda reflexão. Em nome da editora da Revista Espaço Pedagógico da Universidade de Passo Fundo e de todos os leitores que terão acesso a esta entrevista, somos muito gratos pelo tempo que o senhor nos emprestou.

\section{Nota}

1 O presente Diálogo com Educadores contou com a mediação, em nome da Revista Espaço Pedagógico, do Prof. Dr. Altair Alberto Fávero (PPGEdu/UPF) e da Prof ${ }^{a}$ Dra. Gionara Tauchen (PPGEdu/Furg). Ainda, contou com o apoio técnico da doutoranda do PPGEdu/UPF Carina Tonieto. 